Vol. I No. 01Hal. 14 - 20

15 - Januari 2018

\title{
Pengaruh Media Video Pembelajaran Terhadap Hasil Belajar Siswa Pada Sub Materi Spermatophyta di SMA Swasta Nurul Amaliyah Tanjung Morawa Tahun Pembelajaran 2015/2016
}

\author{
Tasmalina, Pandu Prabowo \\ Alumni Program Studi Pendidikan Biologi UISU ${ }^{(1)}$ \\ Dosen Tetap Yayasan FKIP UISU ${ }^{(2)}$
}

\begin{abstract}
ABSTRAK
Penelitian ini bertujuan untuk mengetahui pengaruh Media Video Pembelajaran terhadap hasil belajar siswa pada sub materi Spermatophyta di SMA Swasta Nurul Amaliyah Tanjung Morawa Tahun Pembelajaran 2015/2016. Sampel penelitian ini adalah seluruh siswa kelas X yang terdiri dari 2 kelas dengan jumlah siswa 82 orang yang dipilih satu kelas secara random sampling dan kelas yang terpilih adalah kelas X2 sebanyak 41 siswa. Sampel diberikan pengajaran menggunakan Media Video Pembelajaran dan Metode Quasi eksperimen atau yang disebut juga desain eksprimen semu. Hasil Penelitian menunjukkan bahwa Media Video Pembelajaran dapat meningkatkan hasil belajar siswa. Hal ini ditandai pada saat dilakukan pre-test, $88 \%$ siswa dinyatakan tidak tuntas. Dengan nilai tertinggi 80 sebanyak 5 orang siswa dan nilai terendah 50 sebanyak 5 orang siswa, dengan nilai rata-rata 66,51 dan standart deviasi 9,53. Setelah diberi pengajaran menggunakan Media Video Pembelajaran pada sub materi Spermatophyta (pada post-test) siswa yang mendapat nilai tertinggi 97 sebanyak 2 orang siswa dan nilai terendah 65 sebanyak 2 orang siswa. Maka siswa yang tuntas sebanyak 32 siswa (78\%) dan 9 siswa (22\%) tidak tuntas dengan nilai rata-rata 85,53 dan standart deviasi 8,38. Berdasarkan uji hipotesis didapat nilai thitung $=49,62$ sedangkan nilai ttabel $=1,69$ sehingga 49,62 > 1,69, dengan demikian Ha diterima dan H0 ditolak, dan dapat disimpulkan bahwa ada pengaruh yang signifikan penggunaan Media Video Pembelajaran terhadap hasil belajar siswa pada sub materi Spermatophyta di SMA Swasta Nurul Amaliyah Tanjung Morawa Tahun Pembelajaran 2015/2016.
\end{abstract}

\section{PENDAHULUAN}

\section{LatarBelakang}

Biologi merupakan Ilmu Pengetahuan Alam yang mempelajari semua makhluk hidup yang berhubungan dengan makhluk hidup dan alam sekitar. Biologi membantu manusia mengenal dirinya sebagai organisme, mengenal lingkungannya dan hubungan antara organisme dengan lingkunganya. Dengan mengenal diri dan lingkungan sekitar berarti kita telah belajar ilmu Biologi.Sebagian besar materi pembelajaran Biologi bersifat objektif sehingga untuk mempelajarinya tidak cukup hanya dengan membaca buku dan mendengarkan penjelasan guru. Penjelasan guru dan deskripsi buku dengan gambar yang tidak bergerak tidak cukup untuk bisa lebih memahami pelajaran. Pembelajaran Biologi ini bisa memanfaatkan media komputer yang dapat disajikan dengan menggunakan video agar pembelajaran Biologi lebih menarik lagi untuk dipelajari dan lebih nyata tanpa khayalan.Semakin sadarnya orang akan pentingnya media yang membantu pembelajaran sudah mulai dirasakan. Pengelolaan alat bantu pembelajaran sudah sangat dibutuhkan. Bahkan pertumbuhan ini bersifat gradual. Metamorfosis dari perpustakaan yang menekan pada penyediaan media cetak, menjadi penyediaan permintaan dan pemberian layanan secara multi-sensori dari beragamnya kemampuan individu dalam menyerap informasi, menjadikan pelayanan yang diberikan mutlak wajib bervariatif dan secara luas. Selain itu, dengan semakin meluasnya kemajuan dibidang teknologi, serta ditemukannya dinamika proses belajar maka pelaksanaan kegiatan pendidikan dan pengajaran semakin menuntut dan memperoleh media pembelajaran yang bervariasi secara luas pula (Daryanto, 2011 : 
131).Dengan menggunakan Media Video Pembelajaran guru bisa menyampaikan pelajaran kepada siswa lebih mudah, untuk materi pelajaran yang berhubungan dengan alam, guru tidak harus membawa siswa pergi praktikum lapangan dimana cukup hanya dengan membawa laptop serta mengubungkan dengan proyektor sehingga guru sudah bisa menampilkan video yang berisikan materi pelajaran yang akan dilihat di lapangan. Apabila guru hanya menggunakan metode ceramah dalam pembelajaran Biologi tanpa diiringi oleh media pembelajaran bisa terjadi hal yang tidak dinginkan seperti siswa menghayal teralalu tinggi dan merasa kebingungan. Memang jika guru melakukan praktik lapangan rasa penasaran siswa tersebut bisa terbayar karena siswa bisa melihat secara langsung apa yang dipelajari. Jika melakukan praktikum lapangan makawaktu yang dibutuhkan lebih lama sehingga penggunaan Media Video pembelajaran diharapkan dapat mempersingkat proses pembelajaran agar lebih efesien.Berdasarkan hasil wawancara yang dilakukan di SMA Swasta Nurul Amaliyah Tanjung Morawa dengan guru mata pelajaran Biologi bahwa hasil ulangan harian siswa kelas X mata pelajaran Biologi pada materi Spermatophyta tahun pembelajaran 2014/2015 diketahui hanya 40\% dari 82 siswa yaitu 33 siswa yang mencapai kriteria ketuntasan minimum (KKM) dengan nilai KKM 80,00. Ketidak tuntasan belajar disebabkan oleh kurangnya minat belajar siswa karena siswa mudah merasa bosan dan jenuh jika guru menyampaikan pembelajaran dengan metode ceramah tanpa dikolaborasikan dengan media pembelajaran.Kurangnya memanfaatkan fasilitas sekolah khususnya media pembelajaran yaitu Media Video dimana fasilitas sekolah lengkap dengan proyektor yang sudah terpasang di masing-masing kelas, oleh sebab itu sangat dirugikan jika kita tidak menggunakan fasilitas sekolah yang cukup memadai untuk dapat lebih memudahkan siswa memahami pelajaran yang diajarkan di SMA Swasta Nurul Amaliyah Tanjung Morawa.Berdasarkan dari latar belakang masalah tersebut dan pemilihan media yang sesuai dengan pokok bahasan yaitu pada sub materi Spermatophyta maka penulis tertarik untuk melakukan penelitian yang berjudul "Pengaruh Media Video Pembelajaran Terhadap Hasil Belajar Siswa Pada Sub Materi Spermatophyta Di SMA Swasta Nurul Amaliyah Tanjung Morawa Tahun Pembelajaran 2015/2016”

\section{PerumusanMasalah}

Berdasarkan pembatasan masalah di atas maka perumusan masalah penelitiannya adalah sebagai berikut: Apakah ada pengaruh yang signifikan penggunaan Media Video Pembelajaran terhadap hasil belajar siswa pada Sub Materi Spermatophyta di SMA Swasta Nurul Amaliyah Tanjung Morawa Tahun Pembelajaran 2015/2016.

\section{Tujuan Penelitian}

Adapun yang menjadi tujuan dari penelitian ini adalah :

1. Mengetahui data kemampuan awal siswa sebelum penggunaan Media Video Pembelajaran pada Sub Materi Spermatophyta di SMA Swasta Nurul Amaliyah Tanjung Morawa Tahun Pembelejaran2015/2016.

2. Mengetahui data hasil belajar siswa sesudah menggunakan Media Video Pembelajaran pada Sub Materi Spermatophyta di SMA Swasta Nurul Amaliyah Tanjung Morawa Tahun Pembelejaran2015/2016.

3. Mengetahui ada tidaknya pengaruh Media Video Pembelajaran pada Sub Materi Spermatophyta di SMA Swasta Nurul Amaliyah Tanjung Morawa Tahun Pembelajaran2015/2016. 


\section{Manfaat Penelitian}

Manfaat yang diharapkan sehubungan dengan penelitian ini antara lain :

1. Hasil penelitian ini akan memberikan masukkan bagi guru untuk menerapkan penggunaan Media Video dalam pembelajaran Biologi khusunya pada sub materiSpermathophyta.

2. Hasil penelitian ini akan memberikan masukkan sekolah tempat berlangsungnya penelitian dalam rangka peningkatan kualitaspembelajaran

3. Memberikan kemudahan bagi siswa dalam meningkatkan penguasaan terhadap materi yang mereka pelajari tanpa merasa jenuh, tanpa khayalan, dan tidakmonoton.

4. Hasil penelitian ini akan membuka wasawasan berfikir mahasiswa ketika telah menjadiguru.

5. Dapat digunakan sebagai bahan masukan untuk para peneliti berikutnyayang akan melakukan penelitiansejenisnya.

\section{METODE PENELITIAN}

Langkah-langkah yang dilakukan dalam pengumpulan data adalah sebagai berikut:

\section{Tahap Persiapan}

Prosedur yang ditempuh dalam penelitian ini adalah :

a. Konsultasi dengan dosen pembimbing skripsi.

b. Observasi awal ke kepala sekolah SMA Swasta Nurul Amaliyah Tanjung Morawa membawa surat observasi, apakah diperkenankan melakukan penelitian di tempat tersebut.

c. Setelah mendapatkan izin, berkonsultasi dengan guru Biologi yang mengajar di kelas X tentang materi-materi Biologi yang diajarkan di semester II di kelas X .

d. Penyusunan proposal penelitian.

e. Persetujuan proposal penelitian.

f. Mengurus surat izin penelitian dari FKIP UISU.

g. Melakukan uji coba instrumen tes terhadap soal yang akan diberikan kepada siswa sebagai sampel penelitian.

h. Konsultasi dengan kepala sekolah SMA Swasta Nurul Amaliyah Tanjung Morawa sebagai tempat penelitian dilaksanakan dengan membawa surat izin penelitian.

i. Menyusun materi pembelajaran denganmenerapkanMedia Video Pembelajaran dalam bentuk Rencana Pelaksanaan Pembelajaran (RPP).

j. Membuat kisi-kisi soal dari materi pembelajaran yang akan diujikan.

\section{Tahap Pelaksanaan}

Materi Pelajaran:

Pertemuan I :

a. Memberikan pre-tes

b. Menyajikan materi

c. Melaksanakan pembelajaran dengan menggunakan Media Video Pembelajaran yaitu ciri-ciri Spermatophyta, klasifikasi Spermatophyta serta perbadaan ciri Angiospermae dan Gymnospermae

Pertemuan II:

a. Melanjutkan pembelajaran dengan menggunakan Media Video

b. Memberikan beberapa pertanyaan untuk mengetahui sejauh mana pemahaman siswa tentang materi Spermatophyta. 
c. Menjelaskan tentang materi Spermatophyta dengan menggunakan Media Video Pembelajaran yaitu klasifikasi Angiospermae dan Gymnospermae, perbedaan ciri Dikotil dan Monokotil serta manfaat tumbuhan Spermatophyta bagi kehidupan.

d. Merangkum kembali materi yang telah diajarkan.

e. Memberikan pos-tes kepada siswa

\section{Tahap Penyelesaian}

a. Melakukan pengolahan data

b. Melakukan proses analisis data

c. Menarik kesimpulan

d. Menyusun laporan dengan melengkapi lampiran-lampiran yang berhubungan dengan penelitian

\section{Teknik Analisis Data}

Dalam penelitian yang dilakukan ini data hasil test dapat dikumpulkan setelah selesai test diberikan kepada siswa kemudian dilakukan penskoran.

Langkah-langkah dalam pengolahan data adalah :

Menentukan rata-rata skor masing-masing kelompok dengan menggunakan rumus sebagai berikut : (Sudjana, $2005: 67$ )

1. Menentukan rata-rata skor masing-masing kelompok dengan menggunakan rumus sebagai berikut :

$\overline{\mathrm{x}}=\frac{\Sigma f i x i}{\Sigma f i} \quad$........... (Sudjana: $\left.2005: 67\right)$

Keterangan:

X : Rata-rata

xi : Jumlah skor

fi : Frekuensi

2. Menghitung Standar Deviasi

$S=\frac{\sqrt{n \Sigma f_{i} x_{i}{ }^{2}-\left(\Sigma f_{i} x_{i}\right)^{2}}}{n(n-1)}$.............(Sudjana, $\left.2005: 95\right)$

Keterangan:

$\mathrm{S}$ : Standarat Deviasi

$\mathrm{n}$ : Jumlah Responden

xi : Tanda Kelas

fi : Frekuensi yang sesuai dengan tanda Kelas XI

Uji Persyaratan Analisis Data

\section{Uji Normalitas}

Uji ini bertujuan melihat sampel berdistribusi normal atau tidak. Pengujian normalitas data menggunakan rumus uji lilieforce dengan langkah-langkah sebagai berikut

a. Data $X_{1}, X_{2} \ldots \ldots . X_{n}$ dijadikan bilangan baku, $Z_{1}, Z_{2} \ldots \ldots . Z_{n}$ dengan rumus:

$\mathrm{Z}_{1}=\frac{\mathrm{X}_{1}-\bar{x}}{S}$

$\bar{X}$ dan s masing- masing merupakan rata- rata dan simpangan baku sampel

b. Untuk tiap bilangan baku ini dan menggunakan daftar distribusi normal baku, kemudian dihitung peluang $\mathrm{F}\left(\mathrm{Z}_{\mathrm{i}}\right)=\mathrm{P}\left(\mathrm{Z} \leq \mathrm{Z}_{\mathrm{i}}\right)$.

c. Selanjutnya dihitung proporsi $Z_{1}, Z_{2, \ldots \ldots, Z_{n}}$ yang lebih kecil atau sama dengan $Z_{i}$, jika proporsi ini dinyatakan oleh $\mathrm{S}\left(\mathrm{Z}_{\mathrm{i}}\right)$, maka : 


$$
\mathrm{S}\left(\mathrm{Z}_{\mathrm{i}}\right)=\frac{\text { banyaknya } \mathrm{Z} 1, \mathrm{Z} 2, \ldots \ldots \ldots . \mathrm{Zn} \text { yang } \leq \mathrm{z}_{1}}{N}
$$

d. Hitung selisih $F\left(Z_{i}\right)-S\left(Z_{i}\right)$ kemudian tentukan harga mutlaknya.

e. Ambillah harga yang paling besar diantara harga-harga mutlak selisih tersebut, disebut dengan $\mathrm{L}_{\text {hitung }}$ lalu bandingkan $\mathrm{L}_{\text {hitung }}$ dengan harga mutlak $\mathrm{L}_{\text {tabel }}(\alpha=0,05)$

f. Jika $\mathrm{L}_{\text {hitung }}<\mathrm{L}_{\text {tabel }}$ maka data berdistribusi normal, sedangkan $\mathrm{L}_{\text {hitung }}>\mathrm{L}_{\text {tabel }}$ maka data berdistribusi tidak normal.

Perhitungan uji normalitas dapatdilihat pada lampiran 27 halaman116.

\section{Homogenitas}

Uji homogenitas ini dilakukan untuk mengetahui data pada data yang homogen atau tidak. Untuk menguji homogenitas ini digunakan rumus varians (sudjana, 2002: 250).

$\mathrm{F}_{\text {hitung }}=\frac{\text { Varians terbesar }}{\text { Varians terkecil }}$

atau $\mathrm{F}: \frac{S_{1}^{2}}{S_{2}^{2}}$

$\mathrm{S}_{1}^{2}=$ Varians dari kelompok yang lebih besar

$\mathrm{S}_{2}^{2}=$ Varians dari kelompok yang lebih kecil

kriteria pengujian:

jika $F_{\text {hitung }}<\mathrm{F}_{\text {tabel }}$ maka kedua sampel mempunyai varians yang sama

jika $F_{\text {hitung }}>F_{\text {tabel }}$ maka kedua sampel tidak mempunyai varians yang sama

$\mathrm{F}$ hitung dikonsultasikan dengan tabel distribusi frekuensi $\mathrm{F}_{(\alpha=0,05)}$. Jika $\mathrm{F}_{\text {hitung }}<$ $F_{\text {tabel }}$ maka kedua kelompok sampel berasal dari populasi homogen begitu pula sebaliknya. Perhitungan uji homogenitasdapatdilihat pada lampiran 29 halaman 119.

\section{Uji Hipotesis}

Menguji hipotesis penelitian diterima atau ditolak dilakukan dengan pengujian statistik dengan rumus:

$t=\frac{M d}{\sqrt{\frac{\Sigma X^{2} d}{N(N-1)}}} \ldots \ldots \ldots \ldots . . .$. (Arikunto, 2006:306)

Dengan $\mathrm{Md}=\frac{\sum d}{N}$ dan $\sum x^{2} d=\sum d^{2}-\frac{\left(\sum d\right)^{2}}{N}$

Keterangan:

Md : Mean dari perbedaan pre test dengan post test

$\sum x^{2} d$ : Jumlah Kuadrat Deviasi

$\mathrm{N} \quad$ : Subjek sampel

\section{KESIMPULAN DAN SARAN}

\section{Kesimpulan}

Dari hasil penelitian diatas maka diperoleh kesimpulan sebagai berikut :

1. Nilai rata-rata pre test sebelum menggunakan Media Video Pembelajaran adalah 66,51 dan standart deviasi 9,53. Sebanyak (88\%) siswa tidak tuntas pada sub materi Spermatophyta di kelas X2 SMA Swasta Nurul Amaliyah Tanjung Morawa. Tahun Pembelajaran2015/2016.

2. Nilai rata-rata post test hasil belajar siswa yang diajarkan menggunakan Media Video Pembelajaran adalah 85,53 dan standart deviasi 8,38. Sebanyak 32 orang siswa $(78 \%)$ tuntas dan 9 orang siswa (22\%) tidak tuntas pada sub materi Spermatophyta di kelas X2 SMA Swasta Nurul Amaliyah Tanjung Morawa 
Tahun Pembelajaran2015/2016.Bila dilihat dari nilai pre test dan post test baik nilai rata-rata maupun standart deviasi mengalami peningkatan hasil belajar setelah menggunakan Media Video Pembelajaran.

3. Hasil hipotesis dalam penelitian ini yaitu Ha diterima dan Ho ditolak dengan nilai diperoleh $t_{\text {hitung }}>t_{\text {tabel }}$ atau 49,62 > 1,69. Maka dari hasil analisa terhadap rumusan hipotesis menunjukkan bahwa ada pengaruh yangsignifikan penggunaan Media Video Pembelajaran terhadap hasil belajar siswa pada sub materi Spermatophyta di kelas X2 SMA Swasta Nurul Amaliyah Tanjung Morawa.

\section{Saran}

1. Dari hasil data yang telah di uji pre-test sebanyak 36 orang siswa (88\%) tidak tuntas dan hanya $12 \%$ siswa yang tuntas. Setelah diberi pengajaran menggunakan Media Video menunjukkan adanya pengaruh positif terhadap hasil belajar siswa yaitu sebanyak 32 orang siswa (78\%) yang tuntas dan 9 orang siswa (22\%) tidak tuntas. Dapat dikatakan bahwa penggunaan Media Video Pembelajaran merupakan salah satu solusi untuk meningkatkan hasil belajarsiswa.

2. Diharapkan bagi siswa dapat mempermudah untuk memahami dan menerima materi pembelajaran Biologi khususnya pada sub materiSpermatophyta.

3. Bagi peneliti (calon guru) objek materi pembelajaran yang direkam langsung oleh peneliti akan menambah wawasan bagi peneliti tentang bagaimana cara pembuatan Video Pembelajaran yang baik dan menarik agar siswa mudah mengerti dengan Video yang akan ditampilkan. Objek materi pembelajaran yang direkam dan didesain oleh peneliti secara langsung akan lebihbaik.

4. karena objek yang ditampilkan sesuai dengan kurikulum dan materi ajar sehingga sangat berbeda dengan video yangdidownload melalui media internet.

5. Bagi sekolah yang memiliki fasilitas lengkap hendaknya guru memanfaatkan fasilitas tersebut dengan menampilkan Video Pembelajaran sesuai dengan materi. Membuat Video Pembelajaran yang objeknya direkam sendiri hasilnya lebih sesuai dengan materi yang akandiajarkan.

\section{DAFTAR PUSTAKA}

Arikunto, Suharsini. 2012. Dasar-Dasar Evaluasi Pendidikan . Jakarta:Bumi Aksara.

Arsyad Azhar. 2013. Media Pembelajaran. Jakarta: Rajawali Pers.

Aryulina, dkk. 2007. Biologi 1 SMA dan MA untuk kelas X. Jakarta : Basis.

Daryanto. 2011. Media Pembelajaran. Bandung: Satu Nusa

Departemen Agama RI. Al-Qur'an Tajwid dan Terjemah. (Jakarta: Pustaka AlKautsar, 2009) Q.S. Al-Mujadilah 11, hlm 543.

Departemen Agama RI. Al-Qur'an Tajwid dan Terjemah. (Jakarta: Pustaka AlKautsar, 2009) Q.S. Az-Zumar 9, hlm 459.

Ngalimun. 2014. Strategi dan Model Pembelajaran. Sleman Yogyakarta : Aswaja Pressindo.

Nimah. 2013. Digilig uinsbv.ac.id.

Nurhayati, Nunung 2009. 1700 Bank Soal Bimbingan Pemantapan Biologi Untuk SMA-MA Bandung. CV.Yrama Widya Bandung. 
Tasmalina, Pandu Prabowo : Pengaruh Media Video Pembelajaran Terhadap Hasil Belajar Siswa Pada Sub Materi Spermaotphyta di SMA Swasta Nurul Amaliyah Tanjung Morawa TP. 2015/2016

Sadiman, Rahardjo. 2008. Media Pendidikan. Jakarta: Rajawali Pers.

Sagala, Syaiful. 2008. Konsep dan Makna Pembelajaran. Bandng: Alfabeta.

Sardiman. 2011. Interaksi dan Motivasi Belajar Mengajar. Jakarta: Rajawali Pers.

Sudjana. 2005. Metode Statistika. Bandung. Tarsito.

Susilana, Riyana. 2009. Media Pembelajaran. Bandung: CV Wacana Prima

Pitoyo, Anis. 2013. Biologi untuk SMA/MA Kelas X. Sidoarjo: Masmedia.

Pratiwi, D.A. 2006 Biologi Untuk SMA Kelas X. Jakarta :Erlangga.

Purwanto/ 2011. Evaluasi Hasil Belajar. Yogyakarta: Pustaka Belajar. 